\title{
Effect of a Motor Balance Drills on some biokinematic variables of take-off, side deviation and record level in the long jump competition "Dr/ Mahmoud Abo ELabas Abd ELhamed
}

Introduction and Research Problem

This study aims to identify that Long jump is one of the competitions that have required a remarkable development in its performance and stages to reach the best results using mechanical aspects (kinetic analysis). The long jump is highly depending on many variables, including performance in the suitable manner. Successful performance in the long jump also depends on a high level of coordination between the upper and lower limbs.

Long jump is a competition that requires a great deal of speed and explosive power because of the nature of the long jump competition that requires the generation of maximum strength, and the Drills that are applied in the training should be based on increasing the speed of the approach and takeoff , as well as improving the special technique (flight) used in flight .

To reach the best achievement in the long jump competition, the rider must approach at an optimal speed with good coordination and stable steps to complete the take-off and the body in balance during flight and effective landing.

Each stage of the jump has specific kinetic tasks. Muller, H., \& Ritzdorf, W. (2000) indicate that in the approach phase, horizontal velocity arises, in the take-off phase, also vertical velocity arises, in the flight phase, the equilibrium of the body is maintained for as long as possible in preparation for landing, and in the landing phase. The sand should be touched as far as possible. (19: 88-96)

Soliman Ali Hassan et al. (1983) state that the main objective of approaching It is getting high speed plus good

Lecturer, Department of Physical Training, Faculty of Physical Education, Mansoura University. 
preparation for take-off The goal is not only to have a great speed, but to get it And continue during the last steps before take-off, and the approach is divided internally into two important phases (the stage of graduation in speed the stage of preparation for the take-off ). (4: 119 - Irl)

The take-off stage is one of the difficulties because the center of gravity of the body is shifted from the horizontal to the vertical direction to the flight and resulting from the force of the action of take-off and reaction.

\section{Abdul Rahman}

Zaher (2001) and Qasim Hassan (1999) stated that the take-off is one of the most important and difficult stages in jumping, depending on the distance traveled .In flight it is the main objective of the jump in general and its time is determined when touching the take-off leg of the take-off board and ending when the take-off leg left the board, where it is divided into three stages the placement of the take-off leg on the board - a detailed flexion of the leg of take-off and known as anchor strong propulsion by muscular stretching. (8: 19) (12: 195)

The flight phase starts from the moment the leg of the rider leaves the ground and ends with the landing of the leg in the sandarea. Bastawisi Ahmed (1997) indicated that the purpose of this stage is to maintain the balance of the body, take the center of gravity in its proper motor path and prepare for a good economic landing. (1:12)

Soliman Ali Hassan et al. (1983) explains that the shape of the rider's movement in the flight path is a follow-up movement and preparation for the landing process in accordance with the basic requirements for the feet to move forward together away from the path of the center of gravity of the body in addition to motor balance during the flight phase. The stage of flight and landing in several forms depending on the ability and level of the riders are: squatting - attachment - walking in the air (4: 131)

Walker (1992) stated that the landing process begins when the rider reaches the highest point in the flight curve. Between the heels of the rider while touching the hole and center of gravity.( $r \mathrm{r}: \wedge \vee)$

\section{Aweys Al-Jabali}

(1992) also mentioned the importance of fitness elements order for long jump racers is the characteristic ability of speed - speed - maximum 
power - performance bearing flexibility - (agility, balance, compatibility) (11: 56)

\section{Zatsiorsky, V. M \&}

Kraemer, W. J (2006) show that the abdominal and trunk muscles stabilize the hip and the trunk as they are large and essential muscles that should be trained, especially for athletes, depending on their specialties, because when the hip and spine are strong and stable, Balance is increasing. These muscles should be developed and strengthened, including the flexors and extensors, which twist and rotate, leading to injury prevention. (24: 167)

\section{Adel Abdul Basir (1999) and Miller (1998)} agree that the equilibrium is the ability of an individual to retain his or her body or one of its various parts in a particular position as a result of the harmonic activity of a set of vital organs and systems directed to act against gravitational effects and that to develop equilibrium different movements that can be performed with closed Eyes. (6: 151) (18: 121)

\section{Baumgartner and} Jackson (1999) agree with Carr (1994) that the motor balance is one of the essential physical qualities needed For any successful motor performance, no athletic movement can be performed properly if not connected In terms of equilibrium, whether in the preparatory stage of the skill or the basic stage, as the loss of the balance of the riders during the preparation phase will lead to inaccurate skill performance during the basic stage. (16: 88), (17: 231)

The above shows the importance of motor balance as a basic physical attribute necessary for any successful motor performance in the field and track competitions such as the long jump competition, through the exploratory study carried out by the researcher on a number (3) riders from the distinguished digital level in the competition and registered In the Dakahlia Athletics Zone, the results of kinetic analysis of the take-off stage and the flight phase showed a decrease in the values of some biokinematic variables of the take-off , where the take-off speed ranged from $6.50 \mathrm{~m} / \mathrm{s}$ to 7.35 $\mathrm{m} / \mathrm{s}$, and the take-off angle between $16^{\circ}$ to $17.5^{\circ}$ Having a deviation During the flight phase, the flight deviation distance ranged from $85 \mathrm{~cm}$ to $93 \mathrm{~cm}$ which affected the landing stage and thus the digital level According 
to the Wakai study, Wakai, M., \& Linthorne, NP (2005) (22), Vasilios Panoutsakopoulos et al., (2010) (20).so the researcher use some of Drills for motor balance during the special preparation for the long jump competition, and to know the effect of motor balance Drills on some biokinematic variables of take-off and side deviations during flight and landing.

-Research objectives

identify the impact of

Drills for motor balance on some biokinematic variables of the take-off and side deviations and record level in the long jump competition from:

1- identify the impact of Drills of motor balance on Equilibrium loss time in long jump competition

2- identify the impact of Drills for motor balance on some biokinematic variables in long jump competition

3- identify the impact of Drills for motor balance on side deviations during approach in the long jump competition.

4- identify the impact of Drills for motor balance on side deviations during take-off in the long jump competition.

5- identify the impact of Drills for motor balance on side deviations during flight in the long jump competition.
6- identify the impact of Drills for motor balance on record level in the long jump competition.

\section{- Imposition of the research:}

1- Motor balance Drills positively affect Equilibrium loss time in the long jump competition.

2- Motor balance Drills positively affect some biokinematic variables in the long jump competition.

3- Motor balance Drills positively affect side deviations during approach in the long jump competition.

4- Motor balance Drills positively affect side deviations during take-off in the long jump competition.

5- Motor balance Drills positively affect side deviations during flight in the long jump competition.

6- Motor balance Drills positively affect record level in the long jump competition.

\section{Search Terms:}

- Flight side deviation: the distance between the midpoint of

the

take-off board and the first point of contact in the sand

- Landing loss: the distance between the first contact point in the sand and the point from 
which it was measured. If you find a value of zero it indicates no landing loss.

Related studies in Arabic and English

Included (5) studies

(3) Arabic and (2) English were arranged according to the year of publication of the study starting with Arabic studies and then English:

1- Raafat Abdel Monsef (2004) (3):

Title: Effect of development of motor and muscle balance on side deviations of triple jump distance.

Objective: To investigate the effect of development of motor and muscular balance on side deviations of triple jump distance.

Method used: Experimental

Sample: 16 students from the Faculty of Physical Education Alexandria University who have already learned the triple jump competition and achieved high digital levels

Main results: The development of motor and muscle balance led to the reduction of side deviations, improvement of side deviations led to raise the level of digital achievement.

\section{2- Study: Izzat Ibrahim}

Mahrous (2004) (9):

Title: Effect of Weight

Training and Weight Loss on Some Special Physical Abilities and Digital Level of Long Jump Players.

Objective: To identify the impact of paleometric training and weight training on some special physical abilities and the digital level of long jump players.

Method used: Experimental method.

The sample: (12) players were divided into two groups, one experimental and the other control and the strength of each (6) players.

Main Results: The experimental group outperformed the control group in the level of special physical abilities

\section{3 - Study: the study of Khalid Wahid Ibrahim (2008) (2):}

Title: Relationship between equilibrium loss time and side deviations during the last five steps of transmission and the level of digital achievement of javelin throwers.

Objective: To identify the relationship between equilibrium loss time and side deviations during the last five 
steps of transmission and the level of digital achievement of javelin throwers.

Method used: Descriptive method

Sample: (5) javelin throwers at Mansoura Sports Stadium

Main Results: There is an inverse relationship between the time of equilibrium loss and record level of the javelin throwers. There is also an inverse relationship between side deviations and the level of digital achievement of the javelin throwers.

4. Study: Wakai, M., \& Linthorne, N. P. (2005) (22)

Title: The best take-off angle in the long jump.

Objective: To identify the best take-off angle in the long jump. Method used: Descriptive method

Sample: Three long experienced racers

Main results: Optimal take-off angle for long jump rider is predictable by combining flight range equation with measured relationships between take-off speed and take-off height The prediction method was evaluated using sample video measurements where they performed maximum jump at a wide range of take-off angles

1- To produce low take-off angles, the riders used a long and fast period

2. To produce higher take-off angles, the riders used a shorter and take-offively slower period For the three athletes, the takeoff speed decreased and the take-off height increased when the riders jumped at a higher take-off angle

5- Study: Vassilios

Panoutsakopoulos et al., Panoutsakopoulos, Vassilios, et al (2010) (20):

Title: 3D Biokinematic Analysis of the Preparation Phase for Long Jump Up

Objective: To describe the kinematics of the approach and take-off of the long jump and their impact on flight and landing

Method used: Descriptive method

The sample: eight riders participating in the European Cup Greece 2006.

Main results: The results indicated that all participants used the length of the penultimate step length shortening the last step. Place the take-off leg on the take-off board and the side flight path 
of the center of gravity of the body.

The extent of benefit from associated studies:

The related studies dealt with many topics related to the technical performance of the long jump, where it shed light on a lot of information and results that helped in identifying the most important biokinematic variables of the take-off and flight stage and resulted in some important factors that were taken into account during the design of the training program and research procedures and the presentation and discussion of its results are:

Knowledge of the ideal technical performance of the phases of take-off and flight. These studies have clarified many biokinematic points that affect the correct technical performance during the phases of take-off and flight. It was represented in the height of the center of gravity at the moment of take-off and the speed of take-off and the angle of flight and flight speed.

- The ideal take-off angle in the long jump competition, which achieves the largest jump distance according to some models and the mathematical laws of the jump (22) degree.

The previous studies also dealt with many information on the importance of motor balance and its relationship to the digital level and side deviations as well as some of the Drills used in the training process and the development of models of technical performance.

- The importance of developing the motor balance to reduce side deviations and improve the level of digital achievement Research procedures:

Method used: The experimental approach using two groups, one experimental and one control using the measurement (pre-post).

Area range: Olympic Village and track and field at Mansoura University.

Time range: The survey studies and all research measurements were conducted within the training program of the long jump competition from $r \tau / 1 / 2018$ to $13 / 5 / 2018$.

- The research sample: The research sample was intentionally chosen from the registered athletes in Dakahlia area under (20 years) and with a distinctive digital level in the 
long jump competition. The research sample included (10) riders divided into two groups, one experimental and one control.

Research measurements and tests:

- Basic measurements:

- $\quad$ Age for the nearest half year.

- $\quad$ Length to nearest $\mathrm{cm}$.

- Weight to nearest $\mathrm{kg}$.

- Physical measurements:

1- Maximum power measurements:

- Measure muscle strength of the material to the back.

- Measure the muscle strength of the material for the two legs.
2- Measuring the incremental speed:

- 30m sprint from low start.

3- Measuring the Maximum speed:

- $30 \mathrm{~m}$ sprint of flying start.

4 - Measuring the muscle capacity of the two legs:

- Wide jump test of stability.

- Vertical jump test of stability for Sargent.

5- capacity measurement:

- Shot put in front of the body.

- Shot put from behind the body. (15: 29-32, 84-87, 93-

96)

\section{6- Equilibrium loss time}

Biokinematic variables:
Start of Approach side deviation distance

Distance from take-off line

Landing loss

Actual distance
Length of last step Approach distance

Take-off speed Height of center of gravity Moment of takeoff

Take-off angle

flight deviation distance
Search instruments tools:

- Restameter for measuring height and weight

- Dynamometer for measuring force

- Legal landing area

- Stopwatch (, 01 of a second)
Record level

and - Legal sho

- Tape measure

- 4 cameras

- 4 camera holders

- Tracker

-software for dynamic analysis

SIMI Motion (V 7.5)

- Exploratory study: 
The researcher conducted several studies during the period from $26 / 1 / 2018$ to $27 / 2 / 2018$ in order to develop the training program for the long jump competition and to ensure the suitability of its content to the research sample and to ensure the validity of tools and devices used as well as to organize and control the process of imaging and kinetic analysis.

\section{1- The first exploratory study:}

This study was conducted in the period from $26 / 1 / 2018$ to $25 / 2 / 2018$ with the aim of selecting and determining the content of the training program of the research group and identifying the suitability of the content of its training for the sample, as indicated by specialized scientific references and previous studies. (1) (4) (7) (8) (11) It has been shown that his training is suitable for the research sample under study by applying many of his training to some students outside the research sample, who numbered (3) students from the field and track competitions Advanced.

\section{2- The second exploratory study:}

This study was conducted on 26/2/2018 and aimed at ensuring the validity of the devices and tools used in the research.

\section{3- The third exploratory study:}

This study was conducted on $27 / 2 / 2018$ on a sample of (3) students from the second year outside the research sample in order to organize and control the imaging process has resulted in some of the duties that must be taken into account during the take-off, the most important use of (4) camera In the filming of the same type and the speed of frequency (120) cadre / second and (2) camera placed at a distance (4) meters from the side of the take-off board and perpendicular to it, and the third behind the jump area and perpendicular to the middle of the take-off plate, and both at a height of (125) $\mathrm{cm}$ with a calibration cube Measurement

(1 x $2 \mathrm{~m})$ and a $2 \mathrm{~m}$ measuring beam perpendicular to the center of the take-off board before imaging to determine the scale of the drawing before 
performance, and the fourth to shoot the full distance to determine the jumping course to confirm the form of the measurement and document the imaging fully. As well as the development of some signs during the filming and was confirmed synchronization between the cameras before the start of take-off, using the remote control to operate the cameras at the same time.

\section{Khalid Wahid}

Ibrahim (2008) (2) mentioned from Mohamed Talaat Ibrahim (1984) (14) that the proposed method for measuring the time of equilibrium loss (Sterilites)

Figure (1):

Device description:

* Iron cylinder with holes fixed at distances $(5 \mathrm{~cm})$ in the ceiling and there around another external iron cylinder with holes at distances $(5 \mathrm{~cm})$ can be controlled height with the fixed cylinder by fixing the number (2) screw.

* A spiral section under the outer cylinder with (10) spiral ducts ending from the bottom with an iron base installed on the rolmanbli

* Iron cylinder with holes fixed at distances $(5 \mathrm{~cm})$ in the ceiling and there is another external iron cylinder with holes at distances $(5 \mathrm{~cm})$ can be controlled height with the fixed cylinder by fixing the number (2) screw. - An iron ring with (2) iron handles held by the laboratory and rotating in the spiral ducts (7) cycles.

* Sponge mattress under the device drawn in the middle of a circle diameter $(50 \mathrm{~cm})$.

\section{How it works:}

* Lift the steel ring with the two handles on top of the snails.

* The laboratory is attached to the handles to reach the squat position with the flexion of the head behind and the angle of the torso and thigh (90) degrees with wearing dark glasses do not allow vision.

* The body of the laboratory automatically rotates around the vertical axis seven cycles connected by snails, which regulate the speed of rotation, this situation helps to increase the force of excitement on the balance device directly, and then stands in the middle of the circle under the device.

\section{Measuring Method:}

After the end of the seventh cycle until the laboratory left the device and stand naturally and his foot in the middle of the circle just below the device is calculated this time to the nearest 0.01 of 
the second, this period is called the time of loss of Equilibrium, and repeat this twice and take

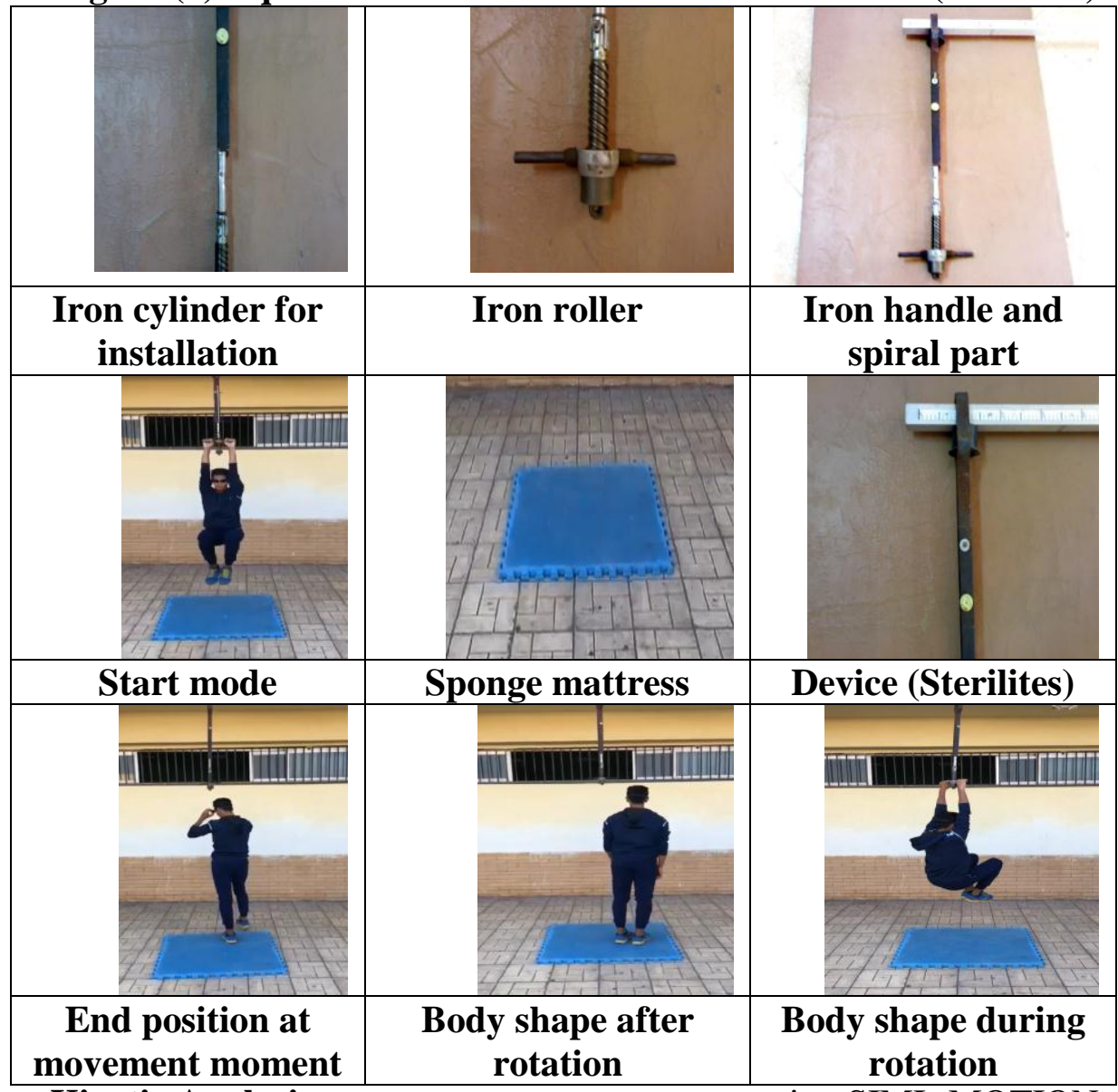

- Kinetic Analysis:

- Preparation of kinetic analysis attempts:

The best successful attempts were identified for each rider from the research sample and were transferred from the cameras to the computer in preparation for the beginning of the analysis the average of the two measurements.

Figure (1) Equilibrium loss time Measurement Device (Sterilites) 
by previous studies (20) (21) (22). SIMI MOTION (V 7.5)

The Tracker program for identifying and extracting biokinematic parameters of the research sample

- The training program is attached (3):

The content of the training program was determined and selected based on the analysis of scientific studies The training programs for the long jump referred to specialized scientific references and associated studies (1) (2) (3) (4) (7) (8) (11) The researcher has trained the two research groups using a training program for a period of (10) weeks, the number of 4

Table (1)

\begin{tabular}{|c|c|c|c|c|c|}
\hline Variables & $\begin{array}{c}\text { measurement } \\
\text { unit }\end{array}$ & Mean & median & $\begin{array}{l}\text { Standard } \\
\text { Deviation }\end{array}$ & $\begin{array}{l}\text { Skewness } \\
\text { coefficient }\end{array}$ \\
\hline Age & year & 11.1 & 19 & $\because \vee \wedge 9$ & $\cdot . \varepsilon \cdot V$ \\
\hline Height & $\mathrm{cm}$ & $1 \wedge \cdot . \wedge$ & IAY.O & $\varepsilon .91 \mathrm{~V}$ & $\cdot V \varepsilon \cdot-$ \\
\hline Weight & $\mathrm{kg}$ & $V V . r$ & $V V$ & $\varepsilon . \Sigma Y T$ & $\cdot . \leqslant 0 r$ \\
\hline $30 \mathrm{~m}$ sprint from low start. & $\mathrm{sec}$ & 4.1090 & 4.085 & 0.1032 & -0.050 \\
\hline $30 \mathrm{~m}$ sprint of flying start. & sec & 3.5010 & 3.500 & .07355 & 0.106 \\
\hline $\begin{array}{l}\text { Muscle strength for } \\
\text { back extensors }\end{array}$ & $\mathrm{kg}$ & 174.20 & 172.5 & 7.0836 & .186 • \\
\hline $\begin{array}{l}\text { Muscle strength for } \\
\text { legs extensors }\end{array}$ & $\mathrm{kg}$ & 217.20 & 219.0 • & 8.2432 & -0.198 \\
\hline Wide jump from stability & $\mathrm{cm}$ & 264.00 & 264.00 & 6.7991 & .999 \\
\hline High jump from stability & $\mathrm{cm}$ & 50.300 & 49.00 & 4.1120 & 0.895 \\
\hline shot put in front of body & $\mathrm{m}$ & 11.520 & 11.525 & 0.4626 & $\cdot .577$ \\
\hline shot put in back of body & $\mathrm{m}$ & 12.160 & 12.200 & $\cdot .4299$ & 0.228 \\
\hline Equilibrium loss time & $\sec$ & 10.156 & 10.00 & 0.6493 & -0.044 \\
\hline
\end{tabular}

Assiut Journal For Sport Science Arts units of training per week in real time For the unit $90-120$ minutes, during the period of private preparation

The training program included a set of free Drills and a set of Drills using tools, as well as the program contains many Drills on the balance of movement.

Pre measurements:

The tribal measurements were carried out during the day of $r \wedge / r / r \cdot 1 \Lambda-1 / r / Y \cdot 1 \Lambda$

Therefore, the values of the research variables of the sample were moderated before starting the experiment as shown in Table (1) and (2). Parity and homogeneity were done for the research sample.

\section{Statistical characterization of study sample in basic and physical variables (under study) $\mathbf{n}=\mathbf{1 0}$} \begin{tabular}{|l|l|l|l|l}
\hline measurement & Mean & & Standard & Skewness \\
\hline
\end{tabular} 
Table (1) show the basic and physical variables for study sample are normally distributed

\author{
Table (2)
}

Statistical characterization of study sample kinematic variables and side deviation before study (under study) $\mathbf{n}=\mathbf{1 0}$

\begin{tabular}{|c|c|c|c|c|c|}
\hline Variables & $\begin{array}{c}\text { measurement } \\
\text { unit }\end{array}$ & Mean & median & $\begin{array}{l}\text { Standard } \\
\text { Deviation }\end{array}$ & $\begin{array}{c}\text { Skewness } \\
\text { coefficient }\end{array}$ \\
\hline $\begin{array}{l}\text { Start of Approach side } \\
\text { deviation distance }\end{array}$ & $\overline{\mathrm{cm}}$ & $r 4.9 .$. & r... . . & T.TYYE & $-\cdot . r$. \\
\hline Length of last step & $\mathrm{cm}$ & 209.41 & 209.65 & 2.50442 & -0.152 \\
\hline $\begin{array}{l}\text { Distance from take- } \\
\text { off line }\end{array}$ & $\mathrm{cm}$ & 7.40 & 7.6000 & .73182 & -0.627 \\
\hline $\begin{array}{l}\text { Take-off side } \\
\text { deviation distance }\end{array}$ & $\mathrm{cm}$ & $10.0 \ldots$ & $10.0 \%$ & T.TYT. & \\
\hline Take-off angle & degree & 16.707 & 16.715 & 0.825 & 0.425 \\
\hline $\begin{array}{l}\text { Height of center of } \\
\text { gravity Moment of } \\
\text { take-off }\end{array}$ & $\mathrm{cm}$ & 105.74 & 106.40 & 2.74963 & -0.917 \\
\hline Take-off speed & $\mathrm{m} / \mathrm{sec}$ & 7.065 & 7.1500 & .51319. & -0.508 \\
\hline $\begin{array}{ll}\text { flight } & \text { deviation } \\
\text { distance } & \\
\end{array}$ & $\mathrm{cm}$ & 88.90 & 89.500 & 2.51440 & -0.226 \\
\hline Landing loss & $\mathrm{cm}$ & 26.20 & 26.500 & 2.44040 & 0.055 \\
\hline Actual distance & $\mathrm{m}$ & 6.399 & 6.4005 & 3.48521 & .011 \\
\hline Record level & $\mathrm{m}$ & 6.063 & 6.0600 & 3.49762 & -0.352 \\
\hline
\end{tabular}

Table (2) show the basic and kinematic variables for study sample are normally distributed

Main study: Conducted during special preparation period of long jump special training program in the period from

$r / r / T \cdot 11$ $-1 \cdot / 0 / Y \cdot 11$ for a period of (10) weeks with $(\xi)$ trainings session a week with repetitions from 90 to $120 \mathrm{~min}$

Post measurements: After completion of main study post- measurements were conducted on $1 \% / 0 / r \cdot 11$

Statistical coefficients and factors: Mean - standard deviation - Median - skewness coefficient - Wilcoxon test $-\mathrm{Z}$ critical value

Results and discussion:

"Identifying the significance of the differences between the results of pre and post measurements in the biokinematic variables, equilibrium loss time and side deviations in the long jump competition: 
Table (3)

significance Differences between pre and post measures for the controlled group in equilibrium loss time- biokinematic variables and side deviations in long jump competition $n 1=n 2=5$

\begin{tabular}{|c|c|c|c|c|c|c|c|c|c|}
\hline \multirow[b]{2}{*}{ Variables } & \multirow{2}{*}{ 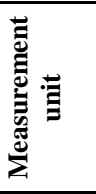 } & \multicolumn{2}{|c|}{$\begin{array}{c}\text { Pre } \\
\text { measurement }\end{array}$} & \multicolumn{2}{|c|}{$\begin{array}{c}\text { Post } \\
\text { measurement }\end{array}$} & \multirow{2}{*}{ 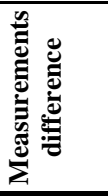 } & \multirow{2}{*}{ 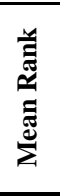 } & \multirow{2}{*}{ 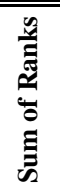 } & \multirow{2}{*}{$\begin{array}{c}Z \\
\text { value }\end{array}$} \\
\hline & & Mean & $\begin{array}{l}\text { Standard } \\
\text { deviation }\end{array}$ & Mean & $\begin{array}{l}\text { Standard } \\
\text { deviation }\end{array}$ & & & & \\
\hline $\begin{array}{l}\text { Equilibrium } \\
\text { loss time }\end{array}$ & $\mathrm{sec}$ & $1 . . r 1 \%$ & . & N.9rr & אידזי. & $-1 . r \wedge$ & $r$ & 10 & *Y.. rr \\
\hline $\begin{array}{c}\text { Start of } \\
\text { Approach side } \\
\text { deviation } \\
\text { distance } \\
\end{array}$ & $\mathrm{cm}$ & r..r... & 3.1145 & v.or. & $r .11 \leq 0$ & $-Y \Lambda . T V$ & $r$ & 10 & $* Y . .+r T$ \\
\hline $\begin{array}{l}\text { Length of } \\
\text { last step }\end{array}$ & $\mathrm{cm}$ & 208.48 & 2.2152 & 203.72 & 2.1005 & -4.76 & r & 10 & *Y..r \\
\hline $\begin{array}{c}\text { Distance } \\
\text { from take-off } \\
\text { line }\end{array}$ & $\mathrm{cm}$ & 7.52 & 0.5215 & 6.32 & 1.1449 & -1.2 & $r$ & 10 & *Y.. rr \\
\hline $\begin{array}{c}\text { Take-off side } \\
\text { deviation } \\
\text { distance } \\
\end{array}$ & $\mathrm{cm}$ & $10 \ldots$ & 2.915 & $1 \ldots$ & 2.916 & $-0 .$. & $r$ & 10 & דצ... \\
\hline $\begin{array}{c}\begin{array}{c}\text { Take-off } \\
\text { angle }\end{array} \\
\end{array}$ & degree & 106.5 & 1.7805 & 111.32 & 2.0474 & 4.82 & $r$ & 10 & *Y..YT \\
\hline $\begin{array}{l}\text { Height of } \\
\text { center of } \\
\text { gravity } \\
\text { Moment of } \\
\text { take-off } \\
\end{array}$ & $\mathrm{cm}$ & 16.83 & 0.927 & 17.35 & 0.6667 & 0.522 & $r$ & 10 & *Y..YT \\
\hline $\begin{array}{c}\text { Take-off } \\
\text { speed }\end{array}$ & $\mathrm{m} / \mathrm{sec}$ & 7.09 & 0.6655 & 7.5 & 0.5477 & 0.41 & r & 10 & 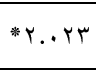 \\
\hline $\begin{array}{l}\text { flight deviation } \\
\text { distance }\end{array}$ & $\mathrm{cm}$ & 88.6 & 2.7019 & 76.200 & 2.5884 & -12.4 & $r$ & 10 & *Y..YT \\
\hline Landing loss & $\mathrm{cm}$ & 25.80 & 2.7749 & 12.530 & 3.4885 & -13.27 & $r$ & 10 & *Y..rT \\
\hline Actual distance & $\mathrm{m}$ & 6.401 & 2.1545 & 6.413 & 1.9718 & 0.011 & $r$ & 10 & *Y..rY \\
\hline Record level & $\mathrm{m}$ & 6.068 & 2.8636 & 6.224 & 4.7582 & 0.156 & $r$ & 10 & *Y..rT \\
\hline $\begin{array}{l}\text { Wilcoxon } \\
\text { Tab } \\
\text { presence } \\
\text { significant } \\
\text { between } \\
\text { measurem } \\
\text { in equil }\end{array}$ & $\begin{array}{l}\text { signif } \\
\text { le (3) } \\
\text { of } \\
\text { pre } \\
\text { ents o } \\
\text { ibriun }\end{array}$ & $\begin{array}{r}\text { ant at } \\
\text { result } \\
\text { stat } \\
\text { diff } \\
\text { and } \\
\text { contrc } \\
\text { loss }\end{array}$ & $\begin{array}{c}.05=8 \\
\text { reveal } \\
\text { stically } \\
\text { rences. } \\
\text { post } \\
\text { group } \\
\text { time }\end{array}$ & & $\begin{array}{l}\text { significa } \\
\text { heasuren } \\
\text { Vilcoxor } \\
\text { ignifican } \\
\text { hile } Z \\
\text { s signif } \\
\text { evel. }\end{array}$ & $\begin{array}{l}t \text { at } 0 . \\
\text { ents } \\
\text { value } \\
\text { e valu } \\
\text { lue w } \\
\text { cance }\end{array}$ & $\begin{array}{l}5= \\
\text { valu } \\
\text { les }\end{array}$ & $\begin{array}{l}1.96 \\
e \\
s \text { th } \\
0.05 \\
\text { eate } \\
e \text { a }\end{array}$ & $\begin{array}{l}\text { where } \\
\text { an its } \\
\text { level } \\
\text { than } \\
0.05\end{array}$ \\
\hline
\end{tabular}

biokinematic variables and side deviation, for the post 
Table (4)

significance Differences between pre and post measures for the experimental group in equilibrium loss time- biokinematic variables and side deviations in long jump competition $n 1=n 2=5$

\begin{tabular}{|c|c|c|c|c|c|c|c|c|c|}
\hline \multirow[b]{2}{*}{ Variables } & \multirow{2}{*}{ 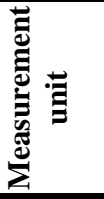 } & \multicolumn{2}{|c|}{ Pre measurement } & \multicolumn{2}{|c|}{ Post measurement } & \multirow{2}{*}{ 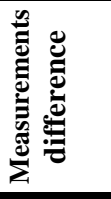 } & \multirow{2}{*}{ 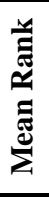 } & \multirow{2}{*}{ 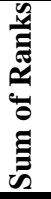 } & \multirow{2}{*}{$\begin{array}{c}\mathrm{Z} \\
\text { value }\end{array}$} \\
\hline & & Mean & $\begin{array}{l}\text { Standard } \\
\text { deviation }\end{array}$ & Mean & $\begin{array}{l}\text { Standard } \\
\text { deviation }\end{array}$ & & & & \\
\hline $\begin{array}{l}\text { Equilibrium } \\
\text { loss time }\end{array}$ & $\mathrm{sec}$ & $1.1 \leq$ &.$\wedge r 90$ & $\varepsilon . \wedge ५ \ldots$ & $. T \leq r V$ & $-0 . Y \Lambda$ & r & 10 & H. \\
\hline $\begin{array}{lr}\text { Start } & \text { of } \\
\text { Approach } & \text { side } \\
\text { deviation } & \\
\text { distance } & \\
\end{array}$ & $\mathrm{cm}$ & rv... & 1.011 & T. . . . & $1 . \Sigma \wedge r$ & $r . . \wedge$. & r & 10 & שr... \\
\hline $\begin{array}{l}\text { Length of } \\
\text { last step }\end{array}$ & $\mathrm{cm}$ & 210.34 & 2.6539 & 200.36 & 2.7172 & -9.38 & 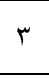 & 10 & * \\
\hline $\begin{array}{l}\text { Distance } \\
\text { from take- } \\
\text { off line }\end{array}$ & $\mathrm{cm}$ & 7.2800 & .94710 & 3.0600 & 1.2935 & -4.22 & r & 10 & * \\
\hline $\begin{array}{l}\text { Take-off side } \\
\text { deviation } \\
\text { distance }\end{array}$ & $\mathrm{cm}$ & $17 . \ldots$ & $1.011 \mathrm{r}$ & $0.1 \ldots$ & I.r. & I. . . . & r & 10 & *Y.IYI \\
\hline $\begin{array}{l}\text { Take-off } \\
\text { angle }\end{array}$ & degree & 104.98 & 3.5209 & 115.52 & 1.7499 & 10.54 & r & 10 & H. r. r \\
\hline $\begin{array}{l}\text { Height of center } \\
\text { of gravity } \\
\text { Moment of take- } \\
\text { off }\end{array}$ & $\mathrm{cm}$ & 16.584 & 0.796 & 19.142 & 0.4663 & 2.56 & r & 10 & * r...r r \\
\hline $\begin{array}{l}\text { Take-off } \\
\text { speed }\end{array}$ & $\mathrm{m} / \mathrm{sec}$ & 7.0400 & .38471 & 8.4700 & .76616 & 1.43 & r & 10 & * \\
\hline $\begin{array}{l}\text { flight deviation } \\
\text { distance }\end{array}$ & $\mathrm{cm}$ & 89.200 & 2.5884 & 34.800 & 5.7184 & -54.40 & r & 10 & H. \\
\hline Landing loss & $\mathrm{cm}$ & 26.600 & 2.3022 & 6.0000 & 1.5811 & -20.60 & r & 10 & *r. . r r \\
\hline $\begin{array}{l}\text { Actual } \\
\text { distance }\end{array}$ & $\mathrm{m}$ & 6.397 & 4.7505 & 6.6086 & 5.7405 & 0.212 & $r$ & 10 & * r.. r r \\
\hline Record level & $\mathrm{m}$ & 6.058 & 4.3244 & 6.5180 & 5.0695 & 0.60 & r & 10 & *r. r r \\
\hline
\end{tabular}

Wilcoxon significant at $0.05=8$ Table (4) results reveal presence of statistically significant differences. between pre and post measurements of experimental group in equilibrium loss time biokinematic variables and side
$\mathrm{Z}$ significant at $0.05=1.96$ deviation, for the post measurements value where Wilcoxon values less than its significance value at 0.05 level while $\mathrm{Z}$ value was greater than its significance value at 0.05 level. 
Table (5)

significance Differences between two post measures for the controlled group and experimental group in equilibrium loss timebiokinematic variables and side deviations in long jump competition $n 1=n 2=5$

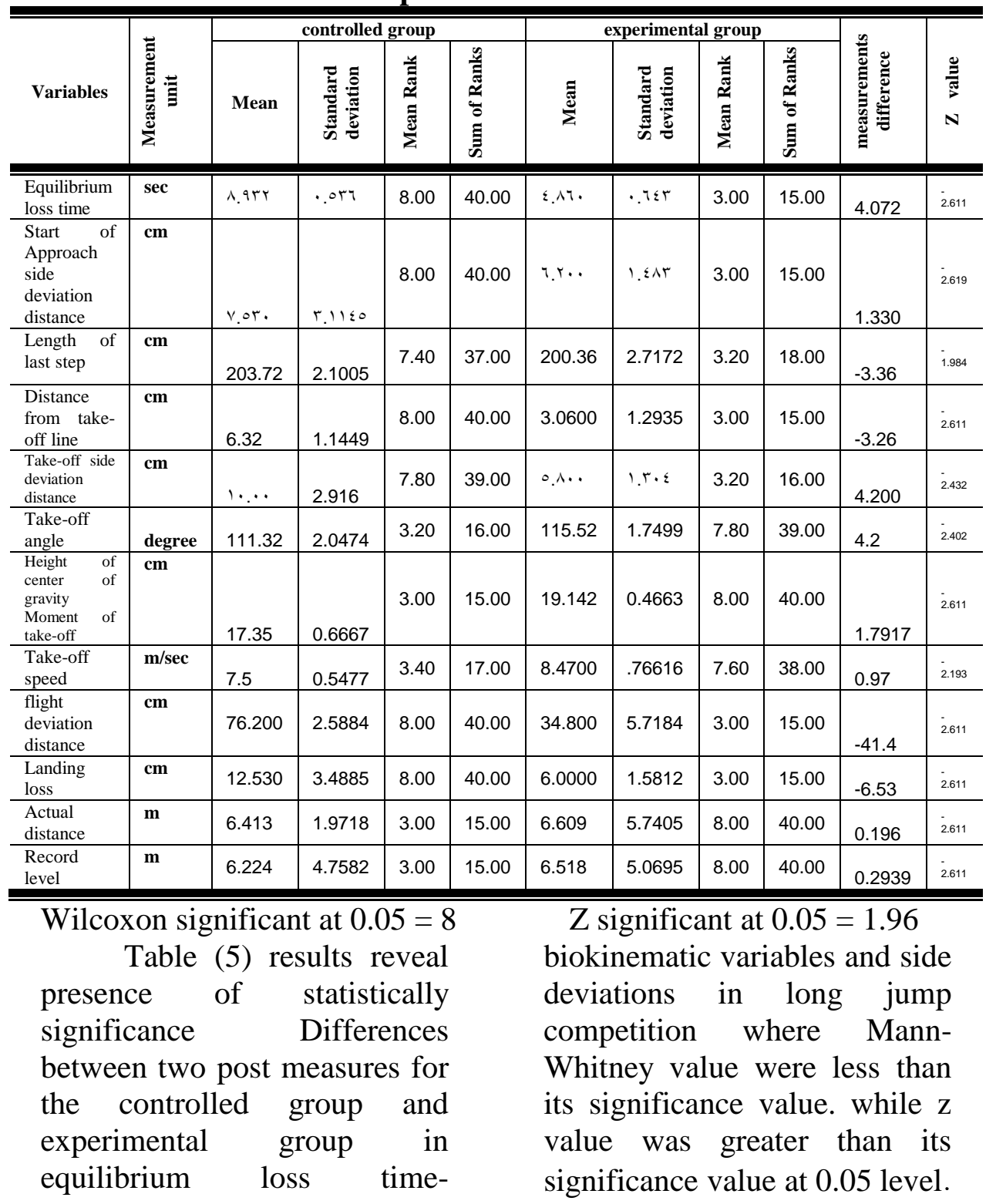




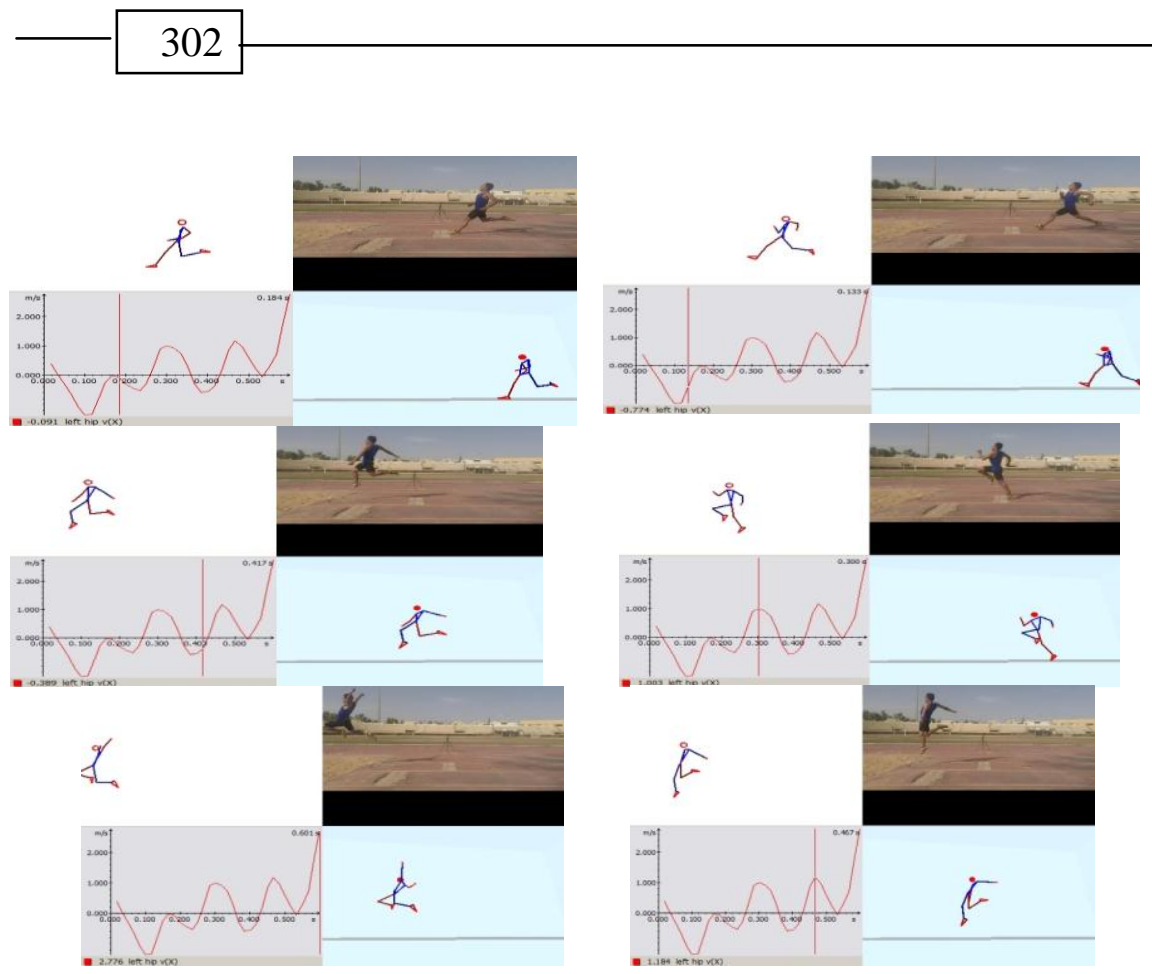

Figure (2) kinetic analysis of some technical points of the last step of the approach and the stages of take-off and flight In the long jump competition for a member of the research sample

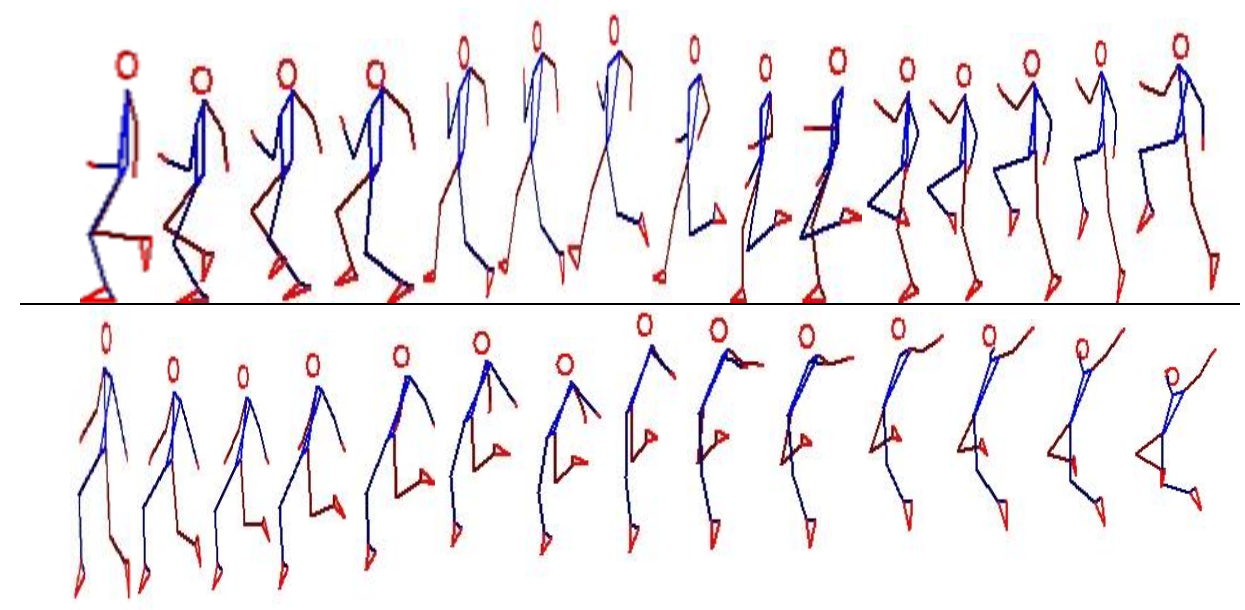

Figure (3) kinetic sequence of the body position during the last step of approach and the take-off and flight 

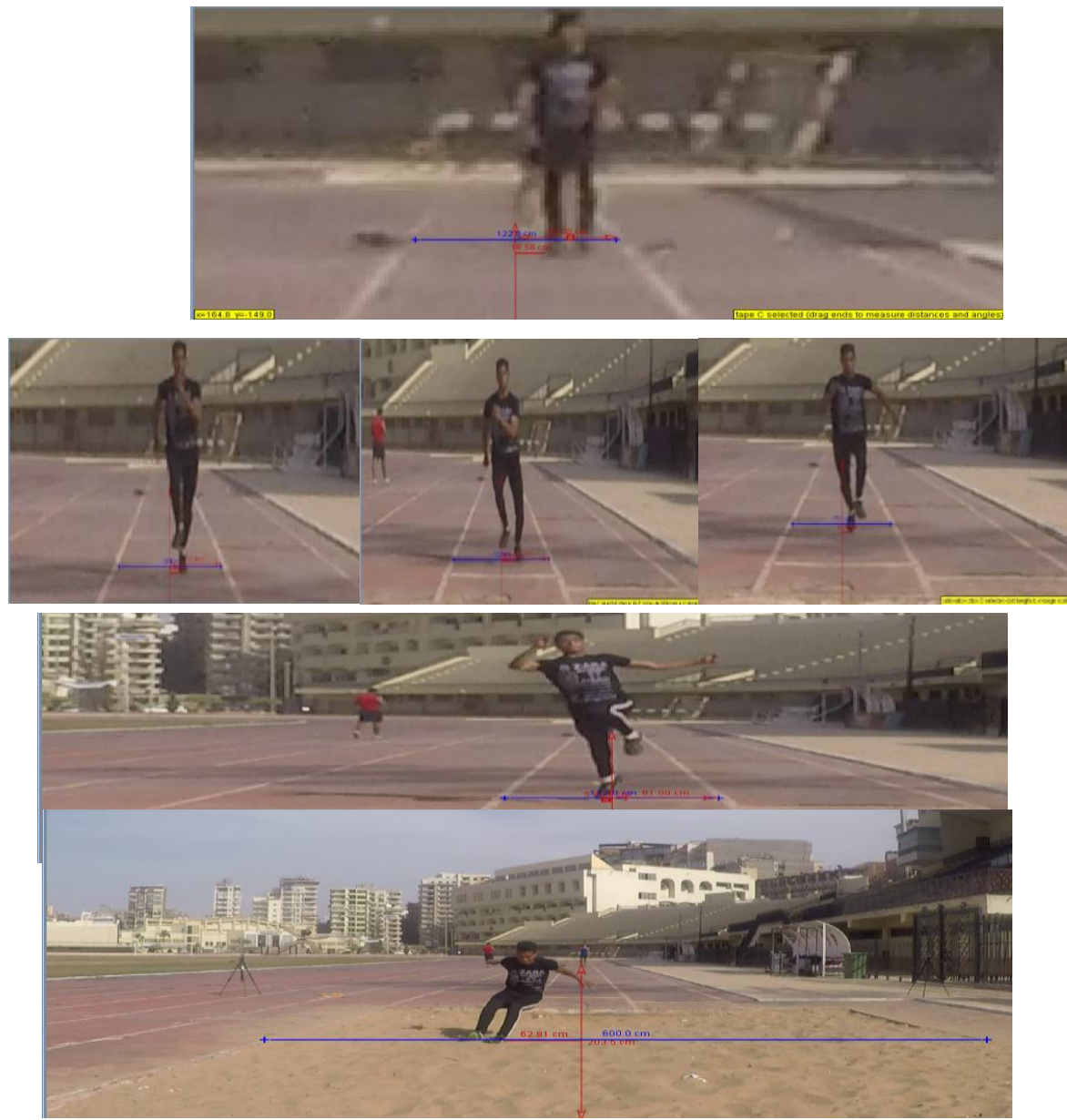

Figure (4) side deviations during flight and landing of some sample members

Second: Discussion of the results: -

1. Discussion of the results of the pre- and postmeasurements of the equilibrium time loss, biokinematic variables under consideration and side deviations in the long jump competition of the control group:

It is clear from Table (3) that there are statistically significant differences at 0.05 level between the pre and post measurement and the control group in the time of equilibrium loss, biokinematic 
variables under consideration and side deviations in the long jump competition for the benefit of telemetry. The standardization used in the traditional training program has helped to improve the equilibrium loss time and technical performance of the approaching, take-off and flight This type of training takes place in the same kinetic course of the long jump competition, which leads to better mobility performance and increase the ability of muscles to contract at a faster rate, and this is consistent with what Talha Hossam al-Din et al. (1997) 5 Both strength and ability are important in most sports activities and are an area to distinguish athletes from each other. Many studies have emphasized the importance of resistance training in the development of muscle strength and ability, especially those Drills that rely on the use of weight training and billiards. And also, with the reference to Bertionen et al. (2000), 21 Traditional Drills have also helped to develop the strength of the muscles behind the thigh, which works to flex the knee and the four-headed femoral muscle that works to extend the knee. This helped to balance these muscle groups, and this is consistent with what Bastawisi Ahmed (1997) (1), and sports training builds multiple experiences that help to develop the motor balance and increase the extent of stability. Essam Abdel Khalek (2005) However, the development of the ability to exert appropriate effort (kinesthetic excellence) means the ability to achieve high and economical accuracy in the effort exerted for motor performance, means to distinguish accurately information on the specifications of spatial movement and the degree of both contractility and diastole of the muscles in the light of the training program to implement the movement and thus develops The spatial perception of movement, the ability to relax and tighten the muscles needed to perform, and the athlete's ability to perform movements in a coordinated manner.

2- Discussion of the results of the pre and post measurements of the time of equilibrium loss, some 
kinematic variables and side deviations of the long jump competition of the experimental group:

It is clear from table

(4) the presence of statistically significant differences at the level 0.05 between the pre and post measurement in the experimental group in the time of equilibrium loss and the biokinematic variables under consideration and side deviations in the long jump competition and for the benefit of telemetry. The Motor balance Drills and standardized plyometric used in the experimental training program have helped to improve the time of equilibrium loss, which is consistent with what Mohamed Talaat Ibrahim (1984) noted. Motor balance Drills also contributed to improving the efficiency of the apparatus, which helped to develop the balance and visual paths of the field of movement as well as maintaining the balance of the body during flight, which led to improved ability to control movement and jump, which is consistent with what was referred to Abdel Halim Mohamed Abdel Halim and others ( 7) Walker
(1992) (23) and Qasim Hassan Hussein et al (2003) (12) where the main objective of the flight phase is to maintain the balance of the body and take the correct motor center of gravity and prepare for a successful economic landing, and this through harmonic movements Both legs and arms, and the shape of these movements is determined by mushy E jump used. The balance Drills also helped to take the body of the rider to the correct positions during the stages of technical performance and also helped to maintain the balance when pushing the ground strongly during the performance, which improved the jump distance

3 - Discussion of the results of post measurements of the time of equilibrium loss, some kinematic variables and side deviations of the long jump competition of the control and experimental groups:

It is clear from Table

(5) that there are statistically significant differences at the level of 0.05 between the post measurements for both experimental and control groups. equilibrium loss time 
$(8.932 \mathrm{~W})$ and the difference between the two groups (4.072 $\mathrm{W})$. The researcher attributed these differences to the positive effect of the motor balance Drills that were applied to the riders, which helped to improve the time of equilibrium loss by improving the efficiency of the balance device in the ear for the riders and this is consistent with what Mohammed Talaat Ibrahim (1984). Keeping the balance inside the ear works to resist the loss of equilibrium as it is responsible for the motor balance and that the time of equilibrium indicates the efficiency of the device to maintain the balance and motor balance of the individual. and increase the range of its stability as shown in Table (5) there are statistically significant differences at the level of 0.05 between the post measurements of the experimental and control groups and in favor of the post measurements of the experimental group in the biokinematic variables under consideration and side deviations in the jump competition.
The mean of the Start of Approach side deviation distance $(6.200 \mathrm{~cm})$ was for the experimental group while the control group was the Start of Approach side deviation distance $(7.530 \mathrm{~cm})$ and the difference between the two groups $(1.330 \mathrm{~cm})$. The mean of the Length of last step $(200.36 \mathrm{~cm})$ was for the experimental group while the control group was the Length of last step $(203.72 \mathrm{~cm})$ and the difference between the two groups $(3.36 \mathrm{~cm})$. The mean of the Take-off side deviation distance $(5.80 \mathrm{~cm})$ was for the experimental group while the control group was the Take-off side deviation distance $(10.00 \mathrm{~cm})$ and the difference between the two groups $(4.20 \mathrm{~cm})$. The height of the center of gravity at the moment of take-off $(115.52 \mathrm{~cm})$ for the experimental group, while the height of the center of gravity at the moment of take-off $(111.32 \mathrm{~cm})$ for the control group and the difference between the two groups (4.2 $\mathrm{cm})$. The take-off speed of the experimental group was $(8.470$ $\mathrm{m} / \mathrm{s}$ ) while the take-off speed was $(7.5 \mathrm{~m} / \mathrm{s})$ for the control group and the difference 
between the two groups $(0.97$ $\mathrm{m} / \mathrm{s}$ ). It was a take-off angle $\left(19.142^{\circ}\right)$ for the experimental group while the take-off angle $\left(17.35^{\circ}\right)$ For the control group and the difference between the two groups $\left(1.7917^{\circ}\right)$. The distance from the take-off line for the experimental group was $(3.06 \mathrm{~cm})$ while the distance from the take-off line $(6.32$ $\mathrm{cm}$ ) for the control group and the difference between the two groups $(3.26 \mathrm{~cm})$. The distance of side deviation during flight was $(34.80 \mathrm{~cm})$ for the experimental group while the distance of side deviation during flight was $(76.20 \mathrm{~cm})$ for the control group and the difference between the two groups $(41.4 \mathrm{~cm})$. The landing loss was for the experimental group $(6.00 \mathrm{~cm})$ while the landing loss $(12.530 \mathrm{~cm})$ was for the control group and the difference between the two groups $(6.53 \mathrm{~cm})$. The actual distance of the experimental group was (6.609 meters) while the actual distance was $(6.413$ meters) for the control group and the difference between the two groups. (0.196 meters). The record level (6.518 meters) for the experimental group, while the record level $(6.224$ meters) for the control group and the difference between the two groups (0.2939 meters). The researcher attributed these differences to the use of the experimental group balance Drills within the training program, while the traditional Drills were applied with the control group. the balance Drills helped to improve the conditions of the body and maintain the rider to balance the body during flight and landing, which led to the reduction of deviation Side Sides This is in agree with what Raafat Abdel Monsef (2004) (3) and Baumgartner \& Jackson (1999) (16) and Carr (1994) (17) agree that motor balance is one of the essential physical qualities necessary for any performance. Successful kinetic movement cannot be performed properly if it is not linked to the equilibrium level, whether in the preparatory stage of the skill or the basic stage as the loss of the equilibrium of the rider during the preparation phase will lead to inaccurate skill performance during the basic stage

The researcher attributed these differences to the use of the experimental 
group balance Drills within the training program where the balance Drills helped to maintain the horizontal speed gained and put the correct takeoff leg on the board and at an angle closer to the optimal technical performance. The various Drills carried out with the closing of the eye helped to develop the motor balance of the riderss and this is consistent with what was explained by Adel Abdul Basir (1999) (5) and Miller (1998) (18) that to develop the balance development can perform different movements with the closure of the eyes.

where the balance Drills helped to maintain the balance of the body and improve the visual paths of the field of movement during flight and this is consistent with what Bastawisi Ahmed (199v) The purpose of this stage is to maintain the balance of the body and take the center of gravity correct motor path and prepare for a good economic landing. The rider's interest after leaving his foot to the ground is to take a path during his flight so as to increase the flight time and put his body in a good position to prepare for the landing process, and this is not done only if the factors affecting the process of flying the center of the rider's body of gravity (speed at the time of take-off, Height of center of gravity, instant take-off , takeoff angle)

Kinetic equilibrium Drills used by the experimental group also reduced side deviations for take-off and flight, which helped in effective landing and thus improved the record level. This is consistent with Walker (1992). Flying, where achieving the ideal path to the center of gravity and in a manner that makes landing in time, is to prolong the flight path as much as possible to achieve the longest possible horizontal distance between the heels of the rider while touching the hole and center of gravity.

\section{Conclusions: -}

In presenting and discussing the results, the following conclusions were reached:

- Drills of motor balance positively affected on Equilibrium loss time in long jump competition 
- Drills of motor balance positively affected on some biokinematic variables in long jump competition

- Drills of motor balance positively affected on side deviations during approach in the long jump competition.

- Drills of motor balance positively affected on side deviations during take-off in the long jump competition.

- Drills of motor balance positively affected on side deviations during flight in the long jump competition.

- Drills of motor balance positively affected on record level in the long jump competition.

Second: Recommendations In the light of the findings of the research, the researchers recommend the following:

* The use of motor balance Drills in programs for the long jump competition.

* Using (Sterilites) device to measure Equilibrium loss time during the stages of training long jump competition.

* Developing Drills for the balance of movement when designing training programs in all competitions field and track, especially competitions that need to maintain balance.

* The need to treat side deviations during the education and training of the long jump competition.

* Attention to motor balance Drills similar to technical performance when designing training programs for the long jump competition.

\section{Arabic and English references:}

\section{First: Arabic References:}

\section{Bastawisy}

Ahmed

Bastawisy (1997): track and field competitions, education, technic, training, Dar Al Fikr Al Arabi, Cairo.

\section{Khaled Wahid Ibrahim}

(2008): The relationship between the time of equilibrium loss and side deviations during the last five steps of transmission and the level of digital achievement of the javelin throwers, published research, scientific journal of the sciences of physical education and sports, the tenth issue, Faculty of Physical Education, Mansoura University.

\section{Raafat Abdel Monsef Ali} (2004): The Effect of Development of Kinetic and Muscular Balance on side 
deviations of Triple Jump Distance, Unpublished PhD Thesis, Faculty of Physical Education for Boys, Alexandria University.

4. Soliman Ali Hassan, Ahmed Mahmoud ElKhadem and Zaki Mohamed Darwish (1983): Scientific analysis of field and track competitions - Dar Al Maaref Cairo.

5. Talha Hossam El-Din, Wafa Salah El-Din, Mustafa Kamel Hamad, Said AbdelRasheed (1997): Encyclopedia of scientific training (strength ability - carrying strength flexibility), the book center for publication and distribution, Cairo.

6. Adel Abdul Basir Ali (1999): mathematical training and integration between theory and practice, the book center for publication.

7. Abdel Halim Mohamed Abdel Halim et al. (2003): Theories and applications of field and track competitions, education, technic, law, Part III, Alexandria.

$\begin{array}{ll}\text { 8. Abdel-Rahman } & \text { Abdel- } \\ \text { Hamid Zaher } & \text { (2000): }\end{array}$ Physiology of Jumping and Jumping Competitions, Book Center for Publishing, Cairo
9. Ezzat Ibrahim El-Sayed Mahrous (2004): The effect of different training using weight and pelletric on some special physical abilities and digital level of long jump players, unpublished doctoral dissertation, Faculty of Physical Education, Tanta University.

10. Essam El-Din Abdel Khalek (2005): sports training (theories _ applications), I 12, the establishment of knowledge, Alexandria.

11. Owais Ali Al-Jabali (1992): Athletics between theory and practice - Socialist Office of the typewriter and scientific photography, Cairo. Helwan University - 1995.

12. Qasim Hassan Hussein et al. (2003): Mechanism of Composite Competitions, 1st Floor, National Library, Bani Ghazi, Libya.

\section{Mohamed Hassan}

Allawi, Mohamed Nasr ElDin Radwan (1994): tests of motor performance, the third edition, Dar Arab thought, Cairo.

\section{Mohamed Talaat}

Ibrahim (1984): Proposed training program to improve the tolerance of the balance 
boxers, Sports for All Conference, Faculty of Physical Education for Boys, Helwan University.

15. Mohamed Lotfy ElSayed (2006): Mathematical Achievement and Rules of Training "An Applied Vision", The Book Center for Publishing, Cairo.

Second: English references:

16. Baumgarther, T.A.,\& Jackson,A.S., (1999):

Measurement for Evaluation in physical Education and Exercise Science, 6th, ed, McGraw Hill, Boston.

17. Carr,C., (1994):

Mechanics of Sport, Apractitioner's Guide, Human Kinetics, Champaign.

18. Miller, D. K., (1998): Measurement by the physical Eductor,3rd,ed, MCG,raw Hill, Boston.

19. Muller, H., \& Ritzdorf, W. (2000). Run, Jump, Throw. The Official Guide to
Teaching Athletics. IAAF Coaches' Edification and Certification System. Munchen: IAAF.

20. Panoutsakopoulos, V., Papaiakovou, G. I., Katsikas, F. S., \& Kollias, I. A. (2010): 3D Biokinematic analysis of the preparation of the long jump take-off. New studies in athletics, 25(1), 55-68.

21. Perttunen, J.O., Kyrolainen, H., \&Komip,H., ( 2000): Biokinematic,

22. Wakai, M., \& Linthorne, N. P. (2005): Optimum take-off angle in the standing long jump. Human movement science, 24(1), 81-96

23. Walker,J.,

(1992):

Triple Jump Ideas, Track and Field Quarterly Review, Vol.42, winter.

24. Zatsiorsky, V. M., \& Kraemer, W. J. (2006): Science and practice of strength training. Human Kinetics. 